\title{
Does SGLT2 Inhibition Affect Sympathetic Nerve Activity in Type 2 Diabetes?
}

\author{
Authors \\ Rumyana Dimova, Tsvetalina Tankova
}

\author{
Affiliation \\ Department of Endocrinology, Medical University of Sofia, \\ Sofia, Bulgaria \\ Key words \\ SGLT2 inhibitor, sympathetic nervous system, type 2 \\ diabetes \\ received 23.07.2020 \\ accepted after revision $\quad 20.10 .2020$ \\ published online $\quad 17.11 .2020$ \\ Bibliography \\ Horm Metab Res 2021; 53: 75-84 \\ DOI $10.1055 / a-1298-4205$ \\ ISSN 0018-5043 \\ (C) 2020. Thieme. All rights reserved. \\ Georg Thieme Verlag KG, Rüdigerstraße 14, \\ 70469 Stuttgart, Germany
}

\author{
Correspondence \\ Rumyana Dimova MD \\ Department of Endocrinology \\ 2, Zdrave Str. \\ Sofia 1431 \\ Bulgaria \\ Tel.: + 359887212 573, Fax: + 35928956210 \\ dr.roumyana.dimova@gmail.com
}

\begin{abstract}
SGLT2 inhibitors increase renal glucose excretion and thus decrease both fasting and postprandial plasma glucose levels. The effects of SGLT2 inhibition outweigh those on glycemic control and are also associated with the induction of hemodynamic changes that improve cardiovascular and renal function in people with type 2 diabetes. The exact mechanisms have not yet been completely clarified. This review is focused on the potential relationship between SGLT2 inhibition and sympathetic nerve activity. There is accumulating evidence for a suppressive effect of SGLT2 inhibitors on the sympathetic nerve tone, which might be a putative mechanism for cardiovascular protection in subjects with type 2 diabetes.
\end{abstract}

\section{The Role of the Kidney in Diabetes and its Chronic Complications}

The kidneys play a key role in glucose homeostasis. They use glucose as a metabolic fuel, produce about $25 \%$ of endogenous glucose, and reabsorb filtered glucose by the sodium-glucose co-transporters SGLT1 and mainly SGLT2 located in the early proximal tubules. The SGLT2 transporter is characterized by low affinity and high capacity. The maximum renal capacity for glucose reabsorption and the renal threshold for glucose are elevated in the diabetes population and, therefore, represent essential mechanisms in the pathogenesis of hyperglycemia. SGLT2 inhibitors counteract these mechanisms, thus, increasing glucose excretion and decreasing both fasting and postprandial plasma glucose levels. Although these effects are insulin independent, they lead to improved insulin secretion and insulin action. The beneficial effects of SGLT2 inhibition outweigh those on glycemic control. Accumulating data have demonstrated that suppressed renal glucose reabsorption results in decline in arterial blood pressure, decrease in the deleteri- ous effect of glucotoxicity and induction of hemodynamic changes that improve cardiovascular and renal function in subjects with type 2 diabetes [1].

Type 2 diabetes is a cardio-metabolic disease leading to the development of micro- and macrovascular complications. While hyperglycemia is a proven major risk factor for microvascular complications such as nephropathy, retinopathy, neuropathy [2,3], the elevated glucose levels are one of the relatively weaker risk factors for macrovascular complications - myocardial infarction, stroke, and peripheral vascular disease [2]. Dyslipidemia, hypertension, obesity, insulin resistance, and prothrombotic state have been recognized as more potent risk factors for macroangiopathy. By 2015 , research data had shown that neither antihyperglycemic medications [4-6] nor lifestyle changes [7] had the potential to reduce cardiovascular risk in people with type 2 diabetes. In recent years, cardiovascular benefits associated with the use of two classes of antihyperglycemic drugs - SGLT2 inhibitors and GLP-1 receptor agonists in patients with type 2 diabetes, have been demonstrated and have changed the overall concept of the choice of antihyperglycemic therapy in type 2 diabetes $[8,9]$. 


\section{Putative Cardio-protective Mechanisms of SGLT2 Inhibition}

The exact mechanisms underlying the cardio-protective role of SGLT2 inhibition is still debatable [10]. Even the landmark CVOT of empagliflozin - EMPA-REG OUTCOME has not explored the specific mechanisms responsible for cardiovascular benefits achieved with the administration of SGLT2 inhibitors.

The hemodynamic effects, such as reduction of arterial blood pressure and arterial stiffness, are due to the potential diuretic effect of SGLT2 inhibition. This is associated with improvement of left ventricular function, by reducing intra- and extracellular volume. Therefore, natriuresis and osmotic diuresis are potential factors that probably contribute to cardiovascular protection. These data have been proven in patients with type 2 diabetes and normal kidney function or the presence of chronic kidney disease stages 1 through 3a [11-22]. However, the osmotic diuresis hypothesis could not explain blood pressure lowering effects of SGLT2 inhibition across the whole spectrum of kidney function deterioration. More recent data from meta-analyses, including studies of patients with more advanced chronic kidney disease stages $3 b-4$, have demonstrated similar reduction of blood pressure, despite the decline in glycosuria in the diabetic population with advanced-stage chronic kidney disease [23]. Although dapagliflozin does not affect $\mathrm{HbA} 1 \mathrm{c}$ level in patients with type 2 diabetes and chronic kidney disease stages 3b-4, it significantly decreases blood pressure and weight in the studied cohort [24]. Therefore, alternate pathways might be considered in the underlying mechanisms, which include the integrated effects of both hemodynamic and metabolic components [23]. One of the involved metabolic factors probably is weight loss, which could account for about $40 \%$ of the change in blood pressure due to SGLT2 inhibition [25, 26].

The ketone hypothesis is also of scientific interest. The transition from glucose to fatty oxidation in the liver increases the plasma concentrations of ketones and they preferentially begin to be used as a fuel in the myocardium. This is considered to be related to improvement of cardiac metabolism and bioenergy [27-30]. The ketogenic hypothesis not only tries to explain the benefits of SGLT2 inhibitors for heart failure risk, but also may partially explain the class antihypertensive effect. Recent data implicate the potential for increased ketones, in particular $\beta$-hydroxybutyrate, associated with SGLT2 inhibition contributing to blood pressure lowering in a murine model [31]. Contrary to the above, some recent data propose the concept that circulating ketone bodies increased by SGLT2 inhibitors ameliorate the inflammatory process thus decreasing CV risk in diabetic patients rather than exert a direct effect on the heart [32]. In line with the above are data from hemodynamic and cardiac function measurements and myocardial uptake of glucose, lactate, free fatty acids or ketones, obtained during regional myocardial ischemia injury followed by reperfusion in healthy swines, which demonstrate the preserving cardiac contractile function independently of myocardial substrate utilization [33]. Since the decrease in HbA1c in EMPA-REG OUTCOME trial was about $0.25 \%$, this improvement in glycemic control could not explain the cardio-protective effect of empagliflozin $[1,8]$. Moreover, the beneficial effect of good glycemic control on cardiovascular risk is expected after many years [34, 35], while a decrease in cardiovascu- lar mortality and hospitalizations for heart failure following administration of empagliflozin have been observed within the first three months. Another potential mechanism is thought to be the expected weight loss and especially the decrease of visceral fat area, which is tightly related to increased insulin sensitivity, but these effects are also unlikely to occur within the first 3 months. Other potential mechanisms that may explain the cardio-protective effect of empagliflozin are the decreased serum uric acid levels, low-grade inflammation, oxidative stress and albuminuria, as well as the activation of angiotensin AT2 receptors, increased glucagon secretion, improved lipid profile, and changes in plasma electrolyte concentration $[1,8,10]$. Convincing evidence in support of these mechanisms is lacking. Moreover, SGLT2 inhibitors have been found to reduce the levels of troponin and the $\mathrm{N}$-terminal fragment of the brain natriuretic peptide prohormone in adults with type 2 diabetes [36]. A direct effect of SGLT2 inhibition on the myocardium has been suggested. SGLT2 inhibitors suppress the myocardial $\mathrm{Na}^{+} / \mathrm{H}^{+}$ transporter, leading to a decrease in cytosolic sodium and vasodilation [37-39]. SGLT2 inhibitors have also been shown to play a role in the production of cytokines and in the decrease of epicardial fat volume [40-42], which is associated with a beneficial effect on myocardial inflammation, necrosis and fibrosis in subjects with type 2 diabetes and visceral obesity $[36,43,44]$. These data require further exploration to determine whether the observed changes are directly related to the cardiovascular benefits in subjects using these drugs [45].

Blood pressure lowering effect of SGLT2 inhibitors seems to be a cornerstone in their cardiovascular protection. SGLT2 inhibitors reduce systolic and diastolic blood pressure and improve its circadian rhythm without any change in heart rate, which is suggested to be based on probable direct suppression of sympathetic nerve activity $[1,10]$. In addition to the negative calorie balance, weight loss and osmotic diuresis, they also suppress sodium-hydrogen antiporter 3, cause proximal tubule osmotic imbalance independently of glycemia, which results in increased tubular $\mathrm{Na}^{+}$secretion.

Since sympathetic hyperactivity is a consequence of insulin resistance and is a typical characteristic of patients with type 2 diabetes, the potential inhibitory effect of these drugs on sympathetic tone might contribute to a reduction in blood pressure and restoration of the normal circadian rhythm and thus play a pivotal role in the reduction of cardiovascular risk [46].

\section{Main Features of Cardiac Autonomic Neuropathy in Diabetes}

Cardiac autonomic neuropathy in subjects with diabetes presents as a sympatho-vagal imbalance with a predominance of sympathetic nerve activity and clinical evidence of decreased heart rate variability, tachycardia at rest, orthostatic hypotension, and increased risk of sudden cardiac death [47]. Tight glycemic control is not sufficient to reduce the risk of cardiac autonomic neuropathy in people with type 2 diabetes. A multifactorial interventions targeting not only glycemia, but other cardiovascular risk factors as well, have been shown to reduce the risk of cardiac autonomic neuropathy by up to $60 \%$ of subjects with type 2 diabetes [48]. 
Cardiac autonomic neuropathy is an independent risk factor for cardiovascular mortality [49]. The ACCORD study in 8000 patients with type 2 diabetes has provided evidence for a 2.14-fold higher risk of overall and cardiovascular mortality in individuals with diabetes and cardiac autonomic neuropathy, after adjusting for traditional cardiovascular risks factors including the use of different classes of medications [50]. Data from other two large studies involving more than 31000 subjects with cardiovascular disease and/ or diabetes, followed for an average of 5 years have demonstrated that heart rate, as an indirect marker of cardiac autonomic function, analyzed as a categorical variable (resting heart rate $<70 \mathrm{bpm}$ and resting heart rate $>70 \mathrm{bpm}$ ), is associated with a significant increase in cardiovascular morbidity and overall mortality [51], and the restoration of autonomic balance is of great importance in decreasing cardiovascular events, heart failure, and early mortality in subjects with diabetes. One of the central mechanisms for the development of cardiac autonomic neuropathy is the impaired hypothalamic regulation due to a dopamine deficiency, which leads to sympathetic dominance, increased insulin resistance and manifestation of the metabolic syndrome. It is considered that some of the newer antihyperglycemic drug classes, namely SGLT2 inhibitors, have the potential to improve autonomic function by reducing sympathetic nerve activity and should be considered when choosing therapy in patients with both diabetes and overt cardiac autonomic neuropathy [52].

\section{Data from Clinical and Animal Studies for the Relation between SGLT2 Inhibition and Sympathetic Nerve Activity}

EMPA-REG OUTCOME study data support the putative suppressive effect of SGLT2 inhibition on sympathetic hyperactivity. This trial has shown no reflex tachycardia despite the reported decrease in vascular volume and significant decline in blood pressure by $2-5 \mathrm{mmHg}$. These findings might be due to a relative reduction of sympathetic nerve activity, nevertheless other neurohormonal factors may also play an important role [8, 53-55]. - Tables $1-3$ present available data from clinical studies regarding the effects of empagliflozin ( $\triangleright$ Table 1 ), dapagliflozin ( $\triangleright$ Table 2 ), canagliflozin ( $\triangleright$ Table 3), and ipragliflozin ( $\triangleright$ Table 3 ) on blood pressure and heart rate. A subanalysis of the studies with luseogliflozin in subjects with type 2 diabetes has not shown any change in heart rate in those with resting heart rate $<70 \mathrm{bpm}$. However, the administration of the drug has been associated with a decrease in heart rate in those with higher resting heart rate $>70 \mathrm{bpm}$, suggesting that SGLT2 inhibitors probably cause a decrease in sympathetic tone only in people with both type 2 diabetes and sympathetic hyperactivity [81, 82].

Data from experimental models are in line with the above mentioned findings in humans. The effect of SGLT2 inhibitors on blood pressure and sympathetic nerve activity has been investigated in animal models with obesity and/or metabolic syndrome and arterial hypertension with impaired circadian rhythm of blood pressure and sympathetic nerve activity. It has been shown that treatment with SGLT2 inhibitors significantly decreases blood pressure and normalizes its circadian rhythm without any change in heart rate.
Therefore, it is considered that the inhibition of SGLT2 transporters might probably improve the circadian rhythm of sympathetic tone through suppression of sympathetic activity mainly during the night [83-85]. Norepinephrine is a major sympathetic neurotransmitter, which up-regulates SGLT2 protein expression in proximal tubule cells and its translocation to the cell surface in humans. Administration of dapagliflozin has been reported to exert a suppressive effect on the norepinephrine turnover in the brown adipose tissue of mice [86]. Moreover, SGLT2 inhibition leads to a decrease in tyrosine hydroxylase and norepinephrine levels in the kidney and heart of murine models, again demonstrating sympathetic nerve inhibitory potential of SGLT2 inhibitors [87, 88]. A direct tubular effect was observed after intraperitoneal injection of luseogliflozin in experimental models without diabetes, regardless of the change in plasma glucose levels and in the absence of hemodynamic renal effects. This is in support of the notion that the mechanism of tubulo-glomerular feedback is unlikely to be triggered [89]. These data provide evidence for an important cross-talk between sympathetic nervous system regulation and SGLT2 inhibition.

\section{SGLT2 Inhibition Counteracts Sympathetic Nerve Hyperactivity - Pros}

In the diabetic population, sympathetic nerve activity is primarily determined by afferent signals from the kidneys, which are richly innervated by chemoreceptors and baroreceptors that send signals to the brain [90]. It is highly likely that the excessive glucose resorption in the proximal renal tubules is involved in the activation of the renal autonomic nerves resulting in central sympathetic hyperactivity. This overstimulation of the sympathetic nervous system might be exacerbated by disruption of the negative feedback mechanism due to the decreased sensitivity of baroreceptor reflexes, which, in turn, increases the efferent sympathetic response to the heart, blood vessels and kidneys [91-94]. The change in the hemodynamics and homeostasis of fluid balance - a major risk factor for heart failure in type 2 diabetes, also contributes to the sympathetic overactivity [82].

It has been suggested that SGLT2 inhibitors decline sympathetic nerve tone through a decrease in the renal afferent nerve activity and suppression of the central reflex mechanisms, which is at the basis of the generalized sympathetic hyperactivity [95], thus exerting a beneficial effect on the hemodynamics of fluid balance. There is significant volume loading in subjects with type 2 diabetes and SGLT2 inhibitor administration leading to subsequent transient osmotic diuresis, which correct it. This phenomenon might be explained by the decrease in the sympathetic nerve outflow to the kidneys. This means that the renal pressure-natriuresis curve shifts to the left [95]. SGLT2 inhibition also corrects hypoxia at the level of the proximal renal tubules, thereby reducing hemodynamic congestion by decreasing sympathetic hyperactivity [82] ( Table 4).

Assuming that after the administration of an SGLT2 inhibitor the load on the heart is reduced by lowering blood pressure, improving its variability, and optimizing fluid volume by improving the renal pressure-diuresis curve; and afterload is diminished due to a 
- Table 1 Available data from clinical studies in type 2 diabetes regarding the effects of empagliflozin on arterial blood pressure and heart rate.

\begin{tabular}{|c|c|c|c|c|c|}
\hline Study & Duration & Dose & $\begin{array}{l}\text { Change in SBP } \\
(\mathrm{mmHg})\end{array}$ & $\begin{array}{l}\text { Change in DBP } \\
(\mathrm{mmHg})\end{array}$ & $\begin{array}{l}\text { Change in HR } \\
\text { (bpm) }\end{array}$ \\
\hline Cherney et al. [57] & 8 weeks & $25 \mathrm{mg}$ & -1.5 & -1.4 & -1.2 \\
\hline Häring et al. [58] & 24 weeks & $\begin{array}{l}10 \mathrm{mg} \\
25 \mathrm{mg}\end{array}$ & $\begin{array}{l}-4.1 \\
-3.5\end{array}$ & $\begin{array}{l}-2.1 \\
-2.2\end{array}$ & No change \\
\hline Chilton et al. [20] & $\begin{array}{l}12 \text { weeks } \\
24 \text { weeks }\end{array}$ & $10 / 25 \mathrm{mg}$ & $\begin{array}{l}-3.9 \\
-1.5\end{array}$ & $\begin{array}{l}-3.6 \\
-1.3\end{array}$ & $\begin{array}{l}-0.6 \\
-0.8\end{array}$ \\
\hline Kovacs et al. [59] & 24 weeks & $\begin{array}{l}10 \mathrm{mg} \\
25 \mathrm{mg}\end{array}$ & $\begin{array}{l}-3.14 \\
-4.00\end{array}$ & $\begin{array}{l}-1.49 \\
-2.21\end{array}$ & No change \\
\hline Nishimura et al. [60] & 4 weeks & $\begin{array}{l}10 \mathrm{mg} \\
25 \mathrm{mg}\end{array}$ & $\begin{array}{l}-4.9 \\
-5.9\end{array}$ & $\begin{array}{l}-1.3 \\
-5.4\end{array}$ & $\begin{array}{l}0.2 \\
-1.7\end{array}$ \\
\hline Häring et al. [61] & 24 weeks & $\begin{array}{l}10 \mathrm{mg} \\
25 \mathrm{mg}\end{array}$ & $\begin{array}{l}-4.5 \\
-5.2\end{array}$ & $\begin{array}{l}-2.0 \\
-1.6\end{array}$ & No change \\
\hline Tikkanen et al. [53] & 12 weeks & $\begin{array}{l}10 \mathrm{mg} \\
25 \mathrm{mg}\end{array}$ & $\begin{array}{l}-2.95 \\
-3.68\end{array}$ & $\begin{array}{l}-1.04 \\
-1.40\end{array}$ & $\begin{array}{l}-0.17 \\
-0.74\end{array}$ \\
\hline Rosenstock et al. [62] & 78 weeks & $\begin{array}{l}10 \mathrm{mg} \\
25 \mathrm{mg}\end{array}$ & $\begin{array}{l}-4.1 \\
-2.4\end{array}$ & $\begin{array}{l}-2.9 \\
-1.5\end{array}$ & No change \\
\hline Rosenstock et al. [63] & 52 weeks & $\begin{array}{l}10 \mathrm{mg} \\
25 \mathrm{mg}\end{array}$ & $\begin{array}{l}-3.4 \\
-3.8\end{array}$ & $\begin{array}{l}-1.2 \\
-2.5\end{array}$ & No change \\
\hline Ferrannini et al. [64] & 78 weeks & $\begin{array}{l}10 \mathrm{mg} \\
25 \mathrm{mg}\end{array}$ & $\begin{array}{r}0.1 \\
-1.7\end{array}$ & $\begin{array}{l}-0.16 \\
-2.2\end{array}$ & No change \\
\hline
\end{tabular}

Adapted from Wan N et al. 2018 [56]. "The studied population is with type 1 diabetes. SBP: Systolic blood pressure; DBP: Diastolic blood pressure; HR: Heart rate.

- Table 2 Available data from clinical studies in type 2 diabetes regarding the effects of dapagliflozin on arterial blood pressure and heart rate.

\begin{tabular}{|c|c|c|c|c|c|}
\hline Study & Duration & Dose & $\begin{array}{l}\text { Change in SBP } \\
(\mathrm{mmHg})\end{array}$ & $\begin{array}{l}\text { Change in DBP } \\
(\mathrm{mmHg})\end{array}$ & $\begin{array}{l}\text { Change in HR } \\
\text { (bpm) }\end{array}$ \\
\hline Wilding et al. [65] & 104 weeks & $\begin{array}{l}5-10 \mathrm{mg} \\
10 \mathrm{mg}\end{array}$ & $\begin{array}{l}-2.6 \\
-2.9\end{array}$ & $\begin{array}{l}-7.5 \\
-4.0\end{array}$ & $\begin{array}{l}-1.3 \\
-1.2\end{array}$ \\
\hline Nauck et al. [66] & 52 weeks & $2.5-10 \mathrm{mg}$ & -4.3 & -1.6 & -0.1 \\
\hline List et al. [67] & 12 weeks & $\begin{array}{l}2.5 \mathrm{mg} \\
5 \mathrm{mg} \\
10 \mathrm{mg} \\
20 \mathrm{mg} \\
50 \mathrm{mg}\end{array}$ & $\begin{array}{l}-3.1 \\
-2.9 \\
-6.4 \\
-4.3 \\
-2.6\end{array}$ & $\begin{array}{r}0.8 \\
-0.3 \\
-2.6 \\
-0.5 \\
0.1\end{array}$ & $\begin{array}{l}-1.4 \\
-1.0 \\
-0.03 \\
1.9 \\
-2.3\end{array}$ \\
\hline $\begin{array}{l}\text { Sjöström et al. [25] } \\
\text { with } \mathrm{AH} \\
\text { without } \mathrm{AH}\end{array}$ & 24 weeks & $10 \mathrm{mg}$ & $\begin{array}{l}-3.6 \\
-2.6\end{array}$ & $\begin{array}{l}-1.2 \\
-1.2\end{array}$ & $\begin{array}{r}-0.5 \\
0.1\end{array}$ \\
\hline Wilding et al. [68] & 48 weeks & $\begin{array}{l}2.5 \mathrm{mg} \\
5 \mathrm{mg} \\
10 \mathrm{mg}\end{array}$ & $\begin{array}{l}-5.30 \\
-4.33 \\
-4.09\end{array}$ & $\begin{array}{l}-2.96 \\
-2.64 \\
-2.85\end{array}$ & $\begin{array}{l}-1.44 \\
-1.25 \\
-0.84\end{array}$ \\
\hline
\end{tabular}

Adapted from Wan N et al. 2018 [56]. SBP: Systolic blood pressure; DBP: Diastolic blood pressure; HR: Heart rate; AH: Arterial hypertension.

moderate vasodilatation and a lack of compensatory tachycardia, the data on decreased incidence of hospitalizations for heart failure and cardiovascular mortality in subjects with type 2 diabetes are not surprising.
More recent data shift the focus from osmotic diuresis to the hypothesis that SGLT2 inhibitors might act like denervation agents in the kidney. It has been shown that renal denervation reduces blood pressure and improves glycemic control in humans [96]. 
- Table 3 Available data from clinical studies in type 2 diabetes regarding the effects of canagliflozin and ipragliflozin on arterial blood pressure and heart rate.

\begin{tabular}{|c|c|c|c|c|c|}
\hline Study & Duration & Dose & $\begin{array}{l}\text { Change in SBP } \\
(\mathrm{mmHg})\end{array}$ & $\begin{array}{l}\text { Change in DBP } \\
(\mathrm{mmHg})\end{array}$ & $\begin{array}{l}\text { Change in HR } \\
\text { (bpm) }\end{array}$ \\
\hline Cefalu et al. [69] & 52 weeks & $\begin{array}{l}100 \mathrm{mg} \\
300 \mathrm{mg}\end{array}$ & $\begin{array}{l}-3.3 \\
-4.6\end{array}$ & $\begin{array}{l}-1.8 \\
-2.5\end{array}$ & $\begin{array}{l}-1.1 \\
-1.2\end{array}$ \\
\hline $\begin{array}{l}\text { Devineni et al. } \\
\text { [70] }\end{array}$ & 4 weeks & $\begin{array}{l}100 \mathrm{mg} \\
300 \mathrm{mg}\end{array}$ & $\begin{array}{r}-10.7 \\
-8.8\end{array}$ & $\begin{array}{l}-7.1 \\
-3.3\end{array}$ & No change \\
\hline $\begin{array}{l}\text { Rosenstock et al. } \\
\text { [71] }\end{array}$ & 12 weeks & $\begin{array}{l}50 \mathrm{mg} \\
100 \mathrm{mg} \\
200 \mathrm{mg} \\
300 \mathrm{mg} \\
2 \times 300 \mathrm{mg}\end{array}$ & $\begin{array}{r}-1.3 \\
1.0 \\
-2.1 \\
-4.9 \\
-3.6\end{array}$ & $\begin{array}{l}-0.1 \\
-0.2 \\
-1.7 \\
-2.1 \\
-2.4\end{array}$ & $\begin{array}{r}-0.2 \\
-0.2 \\
0.6 \\
-1.7 \\
0.2\end{array}$ \\
\hline Leiter et al. [72] & 104 weeks & $\begin{array}{l}100 \mathrm{mg} \\
300 \mathrm{mg}\end{array}$ & $\begin{array}{l}-2.0 \\
-3.1\end{array}$ & $\begin{array}{l}-1.3 \\
-2.2\end{array}$ & $\begin{array}{l}-0.1 \\
-0.2\end{array}$ \\
\hline Sha et al. [73] & 2 weeks & $\begin{array}{l}30 \mathrm{mg} \\
100 \mathrm{mg} \\
200 \mathrm{mg} \\
400 \mathrm{mg} \\
2 \times 300 \mathrm{mg}\end{array}$ & $\begin{array}{r}-10.9 \\
-4.7 \\
-11.5 \\
-9.4 \\
-9.8\end{array}$ & $\begin{array}{r}-3.9 \\
0.2 \\
-4.5 \\
-3.4 \\
-2.9\end{array}$ & $\begin{array}{l}-7.1 \\
-9.7 \\
-5.1 \\
-4.9 \\
-5.5\end{array}$ \\
\hline $\begin{array}{l}\text { Lavalle-González } \\
\text { et al. [74] }\end{array}$ & 52 weeks & $\begin{array}{l}100 \mathrm{mg} \\
300 \mathrm{mg}\end{array}$ & $\begin{array}{l}-3.5 \\
-4.7\end{array}$ & $\begin{array}{l}-1.8 \\
-1.8\end{array}$ & $\begin{array}{l}-1.3 \\
-1.9\end{array}$ \\
\hline Stenlöf et al. [75] & 26 weeks & $\begin{array}{l}100 \mathrm{mg} \\
300 \mathrm{mg}\end{array}$ & $\begin{array}{l}-3.3 \\
-5.0\end{array}$ & $\begin{array}{l}-1.7 \\
-2.1\end{array}$ & $\begin{array}{l}-1.6 \\
-0.5\end{array}$ \\
\hline Wilding et al. [76] & 52 weeks & $\begin{array}{l}100 \mathrm{mg} \\
300 \mathrm{mg}\end{array}$ & $\begin{array}{l}-3.1 \\
-2.9\end{array}$ & $\begin{array}{l}-2.2 \\
-1.7\end{array}$ & $\begin{array}{l}-1.2 \\
-0.4\end{array}$ \\
\hline $\begin{array}{l}\text { Schernthaner et } \\
\text { al. [77] }\end{array}$ & 52 weeks & $300 \mathrm{mg}$ & -5.1 & -3.0 & -0.1 \\
\hline Forst et al. [78] & $\begin{array}{l}26 \text { weeks } \\
52 \text { weeks }\end{array}$ & $\begin{array}{l}100 \mathrm{mg} \\
300 \mathrm{mg} \\
100 \mathrm{mg} \\
300 \mathrm{mg}\end{array}$ & $\begin{array}{l}-5.3 \\
-4.7 \\
-3.4 \\
-3.7\end{array}$ & $\begin{array}{l}-3.3 \\
-3.5 \\
-2.5 \\
-2.7\end{array}$ & $\begin{array}{r}-0.3 \\
-1.3 \\
0.5 \\
-1.0\end{array}$ \\
\hline Yale et al. [79] & 26 weeks & $\begin{array}{l}100 \mathrm{mg} \\
300 \mathrm{mg}\end{array}$ & $\begin{array}{l}-6.1 \\
-6.4\end{array}$ & $\begin{array}{l}-2.6 \\
-3.5\end{array}$ & $\begin{array}{l}-1.9 \\
-1.1\end{array}$ \\
\hline $\begin{array}{l}\text { Maegawa et al. } \\
{[80]^{*}}\end{array}$ & 12 weeks & $25-100 \mathrm{mg}$ & -4.1 & -2.2 & -0.9 \\
\hline
\end{tabular}

Adapted from Wan N et al. 2018 [56]. * The only study with ipragliflozin. SBP: Systolic blood pressure; DBP: Diastolic blood pressure; HR: Heart rate.

Based on these findings, it has been hypothesized that norepinephrine increases SGLT2 expression and thus elevates blood pressure and impairs glucose homeostasis. A more recent study, exploring the direct interaction between sympathetic hyperactivity and SGLT2 regulation in a neurogenic hypertensive mouse model, have reported that downregulation of the renal sympathetic tone via either denervation or SGLT2 inhibition lowers SGLT2 expression and blood pressure. Dapagliflozin decreases tyrosine hydroxylase in heart tissue and norepinephrine content in the kidney without affecting plasma renin levels, indicating a reduced sympathetic nerve function due to SGLT2 inhibition [88].

Other recent studies indicate that some of the potential mechanisms associated with the reduction of sympathetic nerve activity after the administration of an SGLT2 inhibitor are the decreased insulin and leptin levels $[97,98]$, improved insulin sensitivity and decreased hyperinsulinemia, which suppress carotid body activa- tion [99]. Reducing the sodium content that inhibits the activation of organum vasculosum laminae terminalis seems to be another possible mechanism [100] ( $\triangleright$ Table 4).

The putative effect of SGLT2 inhibitors on sympathetic nerve activity is what distinguish them from other diuretics. The main differences with loop and thiazide diuretics are: 1) SGLT2 inhibitors do not lead to reflex activation of the sympathetic nervous system, as there is no increase in heart rate in the presence of a significant decrease in arterial blood pressure; 2 ) thiazide diuretics exert their effects at the level of the distal renal tubules, whereas SGLT2 inhibitors act at the level of the proximal renal tubules, proximally to macula densa, and cause increased natriuresis to the juxtaglomerular apparatus [101,102]; and thiazide and loop diuretics cause hyperglycemia and hyperuricemia, whereas SGLT2 inhibitors decrease plasma glucose and uric acid levels. It has been assumed that SGLT2 inhibitors restore tubular-glomerular feedback, which leads to va- 
- Table 4 The putative mechanisms, which determine the effects of SGLT2 inhibition on the sympathetic nervous system.

\begin{tabular}{|c|c|c|c|}
\hline Central nervous system & Kidney & Heart & Vessels \\
\hline 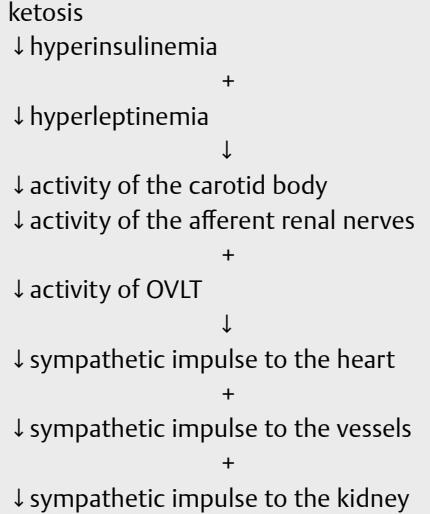 & 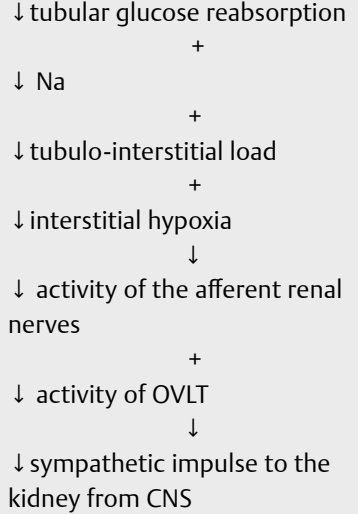 & $\begin{array}{l}\downarrow \text { sympathetic impulse to the } \\
\text { heart } \\
\downarrow \text { volume loading } \\
\downarrow \text { fibrosis } \quad+\end{array}$ & $\begin{array}{l}\downarrow \text { sympathetic impulse to the } \\
\text { vessels } \\
\text { correction of the } \\
\text { fluid retention } \\
\downarrow \text { hypoxia }+ \\
\downarrow \text { RAAS } \quad+ \\
\downarrow \text { neprilyzin activity } \\
\uparrow \text { vascular reactivity } \\
\uparrow \text { natriuretic peptides }\end{array}$ \\
\hline
\end{tabular}

Adapted from Wan N et al. 2018 [56], Sano M. 2017 [83], and Sano M. 2018 [95]. OVLT: Organum vasculosum of the lamina terminalis; CNS: Central nervous system; RAAS: Renin-angiotensin-aldosterone system.

soconstriction of afferent arterioles and reduction of hyperfiltration by decreasing intraglomerular pressure [102]. Increased sodium delivery to macula densa also affects other neuro-hormonal factors such as the renin angiotensin aldosterone system $[46,103]$.

\section{SGLT2 Inhibition Counteracts Sympathetic Nerve Hyperactivity - Cons}

Reduction in arterial blood pressure has been observed in renal transplant patients on SGLT2 inhibitors. Since the transplanted kidney is denervated, this findings reject a direct neurogenic effect of SGLT2 inhibition [104]. The reduced plasma volume has been suggested to be the most likely underlying mechanism in this case. Plasma volume is tightly controlled, rapidly recovering when altered through multiple compensatory mechanisms. Just a $5 \%$ decrease in plasma volume is necessary to activate the sympathetic nervous system and the renin angiotensin aldosterone system and to suppress natriuretic peptides, which results in activation of water and sodium reabsorption in the kidney and recovery of baseline plasma volume. The increase of plasma osmolality is also related to fluid release into the extracellular space. Plasma volume is retained reduced even after years of treatment with SGLT2 inhibitors, because the osmotic effect of glucose and the presence of more sodium outside the proximal renal tubules is perceived by the nephron as a sign of excessive filtration, such as this occurs with increased plasma volume or sodium retention. In fact, plasma volume and sodium are not increased [105], and even the total amount of sodium in the body is reduced after administration of an SGLT2 inhibitor [14]. Nevertheless, these signs result in homeostatic changes, including a new steady state of the body associated with reduced plasma volume [105].

Contrary to the above, data from some studies have implied not only the lack of effect on sympathetic nerve activity, but also stimulation of the sympathetic nerve tone as a result of SGLT2 inhibi- tion. Some previous studies have shown that the increased hepatic glucose production, observed in subjects treated with dapagliflozin, cannot be explained only by insulin suppression and direct stimulation of glucagon by alpha cells [106]. It has been presumed that this process might be mediated by stimulation of the renal sympathetic nerves, which communicate directly with the liver through the portal bloodstream, or might be indirectly stimulated by the renal sympathetic nerves via impulses to the central nervous system and subsequently generation of efferent signals to the liver [107]. In line with this, two other studies have not demonstrated a beneficial effect of the combination of a DPP-4 inhibitor and an SGLT2 inhibitor on glucose levels, highlighting the role of other factors beyond elevated glucagon levels and decreased insulin levels, such as renal sympathetic nerve activation, which is likely to play a significant role in stimulating liver glucose production $[108,109]$. However, if the effects on glucagon have been associated with generalized sympathetic nerve hyperactivity, the heart rate would have increased rather than decreased in the EMPAREG OUTCOME study [55].

A study in patients with type 1 diabetes without chronic complications treated with empagliflozin, applying clamp technique, has shown that heart rate variability and plasma adrenaline and norepinephrine concentrations remain unchanged in both clamps under euglycemic and hyperglycemic conditions [57]. There has also been no change in muscle sympathetic nerve activity and heart rate, despite increased urine volume, following short-term administration of emagliflozin in patients with type 2 diabetes [110]. Therefore, further prospective studies focusing on the relationship between SGLT2 inhibition and sympathetic nervous system function are needed. Data from EMBODY trial, a prospective, multicenter, randomized, double-blind, placebo-controlled study in patients with acute myocardial infarction and type 2 diabetes, will add further clarity on the effect of empagliflozin on sympathetic nerve activity [111]. 


\section{Conclusion}

In summary, there is accumulating evidence on the putative suppressive effect of SGLT2 inhibition on sympathetic nerve activity in subjects with type 2 diabetes, but still there are a lot of controversies and a need for further research in the field to address this issue and to answer the unresolved questions.

\section{Acknowledgements}

This work is supported by the Bulgarian Ministry of Education and Science under the National Program for Research "Young Scientists and Postdoctoral Students".

\section{Conflict of Interest}

The authors declare that they have no conflict of interest.

\section{References}

[1] De Fronzo RA, Norton L, Abdul-Ghani M. Renal, metabolic and cardiovascular considerations of SGLT2 inhibition. Nat Rev Nephrol 2017; 13: 11-26

[2] UK Prospective Diabetes Study (UKPDS) Group. Intensive blood-glucose control with sulphonylureas or insulin compared with conventional treatment and risk of complications in patients with type 2 diabetes (UKPDS 33). Lancet 1998; 352: 837-853

[3] The Diabetes Control and Complications Trial Research Group. The effect of intensive treatment of diabetes on the development and progression of long-term complications in insulin-dependent diabetes mellitus. N Engl J Med 1993; 329: 977-986

[4] Action to Control Cardiovascular Risk in Diabetes Study Group. Effects of intensive glucose lowering in type 2 diabetes. $N$ Engl J Med 2008; 358: 2545-2559

[5] Patel A, MacMahon S, Chalmers J et al. Intensive blood glucose control and vascular outcomes in patients with type 2 diabetes. N Engl J Med 2008; 358: 2560-2572

[6] Duckworth Abraira C, Thomas Moritz T et al. Glucose control and vascular complications in veterans with type 2 diabetes. N Engl J Med 2009; 360: 129-139

[7] Look Ahead Research Group. Eight-year weight losses with an intensive lifestyle intervention: The look AHEAD study. Obesity (Silver Spring) 2014; 22: 5-13

[8] Zinman B, Wanner C, Lachin JM et al. Empagliflozin, cardiovascular outcomes, and mortality in type 2 diabetes. N Engl J Med 2015; 373 : 2117-2128

[9] Marso SP, Daniels GH, Brown-Frandsen K et al. Liraglutide and cardiovascular outcomes in type 2 diabetes. N Engl J Med 2016; 375 : 311-322

[10] Inzucchi SE, Zinman B, Wanner C et al. SGLT-2 inhibitors and cardiovascular risk: Proposed pathways and review of ongoing outcome trials. Diab Vasc Dis Res 2015; 12: 90-100

[11] Verma S, McMurray JJV, Cherney DZI. The metabolodiuretic promise of sodium-dependent glucose cotransporter 2 inhibition: The search for the sweet spot in heart failure. JAMA Cardiol 2017; 2: 939-940

[12] Sattar N, McLaren J, Kristensen SL et al. SGLT2 inhibition and cardiovascular events: Why did EMPA-REG Outcomes surprise and what were the likely mechanisms? Diabetologia 2016; 59: 13331339
[13] Lytvyn Y, Bjornstad P, Udell JA et al. Sodium glucose cotransporter-2 inhibition in heart failure: Potential mechanisms, clinical applications, and summary of clinical trials. Circulation 2017; 136: 1643-1658

[14] Karg MV, Bosch A, Kannenkeril D et al. SGLT-2-inhibition with dapagliflozin reduces tissue sodium content: A randomized controlled trial. Cardiovasc Diabetol 2018; 17: 5

[15] Inzucchi SE, Zinman B, Fitchett D et al. How does empagliflozin reduce cardiovascularmortality? Insights from a mediation analysis of the EMPA-REG OUTCOME trial. Diabetes Care 2018; 41: 356-363

[16] Lambers Heerspink HJ, de Zeeuw D, Wie L et al. Dapagliflozin a glucose-regulating drug with diuretic properties in subjects with type 2 diabetes. Diabetes Obes Metab 2013; 15: 853-862

[17] Hallow KM, Helmlinger G, Greasley PJ et al. Why do SGLT2 inhibitors reduce heart failure hospitalization? A differential volume regulation hypothesis. Diabetes Obes Metab 2018; 20: 479-487

[18] Wilcox CS, Shen W, Boulton DW et al. Interaction between the sodium-glucose-linked transporter 2 inhibitor dapagliflozin and the loop diuretic bumetanide in normal human subjects. J Am Heart Assoc 2018; 7: e007046

[19] Striepe K, Jumar A, Ott C et al. Effects of the selective sodium-glucose cotransporter 2 inhibitor empagliflozin on vascular function and central hemodynamics in patients with type 2 diabetes mellitus. Circulation 2017; 136: 1167-1169

[20] Chilton R, Tikkanen I, Cannon CP et al. Effects of empagliflozin on blood pressure and markers of arterial stiffness and vascular resistance in patients with type 2 diabetes. Diabetes Obes Metab 2015; 17: 1180-1193

[21] Li H, Shin SE, Seo MS et al. The anti-diabetic drug dapagliflozin induces vasodilation via activation of PKG and Kv channels. Life Sci 2018; 197: 46-55

[22] Solini A, Giannini L, Seghieri M et al. Dapagliflozin acutely improves endothelial dysfunction, reduces aortic stiffness and renal resistive index in type 2 diabetic patients: A pilot study. Cardiovasc Diabetol 2017; 16: 138

[23] Sternlicht H, Bakris GL. Blood pressure lowering and sodium-glucose co-transporter 2 inhibitors (SGLT2is): More than osmotic diuresis. Curr Hypertens Rep 2019; 21: 12

[24] Dekkers C], Wheeler DC, Sjöström CD et al. Effects of the sodium-glucose co-transporter 2 inhibitor dapagliflozin in patients with type 2 diabetes and stages 3b-4 chronic kidney disease. Nephrol Dial Transplant 2018; 33: 2005-2011

[25] Sjostrom CD, Johansson P, Ptaszynska A et al. Dapagliflozin lowers blood pressure in hypertensive and non-hypertensive patients with type 2 diabetes. Diabetes Vasc Dis Res 2015; 12: 352-358

[26] Cefalu WT, Stenlöf K, Leiter LA et al. Effects of canagliflozin on body weight and relationship toHbA1c and blood pressure changes in patients with type 2 diabetes. Diabetologia 2015; 58: 1183-1187

[27] Ferrannini E, Mark M, Mayoux E. CV protection in the EMPA-REC Outcome Trial: A “Thrifty Substrate” hypothesis. Diabetes Care 2016; 39: $1108-1114$

[28] Lopaschuk GD, Verma S. Empagliflozin's fuel hypothesis: Not so soon. Cell Metab 2016; 24: 200-202

[29] Santos-Gallego CG, Ibanez JAR, San Antonio R et al. Empagliflozin induces a myocardial metabolic shift from glucose consumption to ketone metabolism that mitigates adverse cardiac remodeling and improves myocardial contractility. J Am Coll Cardiol 2018; 71: A674. Abstract

[30] Kappel BA, Lehrke M, Schutt K et al. Effect of empagliflozin on the metabolic signature of patients with type 2 diabetes mellitus and cardiovascular disease. Circulation 2017; 136: 969-972

[31] Chakraborty S, Galla S, Cheng X et al. Saltresponsive metabolite, $\beta$-hydroxybutyrate, attenuates hypertension. Cell Rep 2018; 25: 677-689 
[32] Prattichizzo F, De Nigris V, Micheloni S et al. Increases in Circulating Levels of Ketone Bodies and Cardiovascular Protection With SGLT2 Inhibitors: Is Low-Grade Inflammation the Neglected Component? Diabetes Obes Metab 2018; 20: 2515-2522

[33] Baker HE, Kiel AM, Luebbe ST et al. Inhibition of sodium-glucose cotransporter-2 preserves cardiac function during regional myocardial ischemia independent of alterations in myocardial substrate utilization. Basic Res Cardiol 2019; 114: 25

[34] Holman R, Paul S, Bethel M et al. A. 10-year follow-up of intensive glucose control in type 2 diabetes. N Engl J Med 2008; 359: 1577-1589

[35] Hayward RA, Reaven PD, Emanuele NV et al. Follow-up of glycemic control and cardiovascular outcomes in type 2 diabetes. N Engl J Med 2015; 372: 2197-2206

[36] Januzzi JL Jr, Butler J, Jarolim P et al. Effects of canagliflozin on cardiovascular biomarkers in older adults with type 2 diabetes. J Am Coll Cardiol 2017; 70: 704-712

[37] Packer M, Anker SD, Butler ] et al. Effects of sodium-glucose cotransporter 2 inhibitors for the treatment of patients with heart failure: Proposal of a novel mechanism of action. JAMA Cardiol 2017; 2: 1025-1029

[38] Uthman L, Baartscheer A, Bleijlevens B et al. Class effects of SGLT2 inhibitors in mouse cardiomyocytes and hearts: Inhibition of $\mathrm{Na}+\mathrm{H}+$ exchanger, lowering of cytosolic $\mathrm{Na}+$ and vasodilation. Diabetologia 2018; 61: 722-726

[39] Baartscheer A, Schumacher CA, Wust RC et al. Empagliflozin decreases myocardial cytoplasmic $\mathrm{Na}+$ through inhibition of the cardiac $\mathrm{Na}+/ \mathrm{H}+$ exchanger in rats and rabbits. Diabetologia 2017; 60: $568-573$

[40] Packer M. Do sodium-glucose co-transporter-2 inhibitors prevent heart failure with a preserved ejection fraction by counterbalancing the effects of leptin? A novel hypothesis. Diabetes Obes Metab 2018; 20: 1361-1366

[41] Timothy Garvey W, Van Gaal L, Leiter LA et al. Effects of canagliflozin versus glimepiride on adipokines and inflammatory biomarkers in type 2 diabetes. Metabolism 2018; 85: 32-37

[42] Sato T, Aizawa Y, Yuasa S et al. The effect of dapagliflozin treatment on epicardial adipose tissue volume. Cardiovasc Diabetol 2018; 17: 6

[43] Lee TM, Chang NC. Lin SZ. Dapagliflozin, a selective SGLT2 inhibitor, attenuated cardiac fibrosis by regulating the macrophage polarization via STAT3 signaling in infarcted rat hearts. Free Radic Biol Med 2018; 104: 298-310

[44] Kang S, Verma S, Teng G et al. Direct effects of empagliflozin on extracellular matrix remodeling in human cardiac fibroblasts: Novel translational clues to EMPA-REG Outcome. Can J Cardiol 2017; 33 : S169 Abstract

[45] Fukuda T, Bouchi R, Terashima M et al. Ipragliflozin reduces epicardial fat accumulation in non-obese type 2 diabetic patients with visceral obesity: a pilot study. Diabetes Ther 2017; 8: 851-861

[46] Wilcox C. Antihypertensive and Renal Mechanisms of SGLT2 (Sodium-Glucose Linked Transporter 2) Inhibitors. Hypertension 2020; 75: 894-901

[47] Pop-Busui R, Boulton A, Feldman E et al. Diabetic neuropathy: A position statement by the American Diabetes Association. Diabetes Care 2017; 40: 136-154

[48] Gaede P, Vedel P, Larsen N et al. Multifactorial intervention and cardiovascular disease in patients with type 2 diabetes. $N$ Engl J Med 2003; 348: 383-393

[49] Maser RE, Mitchell BD, Vinik Al et al. The association between cardiovascular autonomic neuropathy and mortality in individuals with diabetes: A meta-analysis. Diabetes Care 2003; 26: 1895-1901
[50] Pop-Busui R, Evans GW, Gerstein HC et al.Action to Control Cardiovascular Risk in Diabetes Study Group. Effects of cardiac autonomic dysfunction on mortality risk in the Action to Control Cardiovascular Risk in Diabetes (ACCORD) trial. Diabetes Care 2010; 33: $1578-1584$

[51] Lonn EM, Rambihar S, Gao P et al. Heart rate is associated with increased risk of major cardiovascular events, cardiovascular and allcause death in patients with stable chronic cardiovascular disease: An analysis of ONTARGET/ TRANSCEND. Clin Res Cardiol 2014; 103 : 149-159

[52] Vinik A, Casellini C, Parson H et al. Cardiac autonomic neuropathy in diabetes: A predictor of cardiometabolic events. Front Neurosci 2018; 12: 591

[53] Tikkanen I, Narko K, Zeller C et al. Empagliflozin reduces blood pressure in patients with type 2 diabetes and hypertension. Diabetes Care 2015; 38: 420-428

[54] Baker WL, Smyth LR, Riche DM et al. Effects of sodium-glucose cotransporter 2 inhibitors on blood pressure: A systematic review and meta-analysis. J Am Soc Hypertens 2014; 8: 262-275

[55] Abdul-Ghani M, Del Prato S, Chilton R et al. SGLT2 inhibitors and cardiovascular risk: Lessons learned from the EMPAREG OUTCOME study. Diabetes Care 2016; 39: 717-725

[56] Wan N, Rahman A, Hitomi H et al. The effects of sodium-glucose cotransporter 2 inhibitors on sympathetic nervous activity. Front Endocrinol 2018; 9: 421

[57] Cherney DZ, Perkins BA, Soleymanlou $\mathrm{N}$ et al. The effect of empagliflozin on arterial stiffness and heart rate variability in subjects with uncomplicated type 1 diabetes mellitus. Cardiovasc Diabetol 2014; $13: 28$

[58] Haring HU, Merker L, Seewaldt-Becker E et al. Empagliflozin as add-on to metformin plus sulfonylurea in patients with type 2 diabetes: a 24-week, randomized, double-blind, placebo-controlled trial. Diabetes Care 2013; 36: 3396-3404

[59] Kovacs CS, Seshiah V, Swallow R et al. Empagliflozin improves glycaemic and weight control as add-on therapy to pioglitazone or pioglitazone plus metformin in patients with type 2 diabetes: $\mathrm{A}$ 24-week, randomized, placebo-controlled trial. Diabetes Obesity Metab 2014; 16: 147-158

[60] Nishimura R, Tanaka Y, Koiwai K et al. Effect of empagliflozin monotherapy on postprandial glucose and 24-hour glucose variability in Japanese patients with type 2 diabetes mellitus: A randomized, double-blind, placebo-controlled, 4-week study. Cardiovasc Diabetol 2015; 14: 11

[61] Haring HU, Merker L, Seewaldt-Becker E et al. Empagliflozin as add-on to metformin in patients with type 2 diabetes: A 24-week, randomized, double-blind, placebo-controlled trial. Diabetes Care 2014; 37: 1650-1659

[62] Rosenstock J, Jelaska A, Zeller C et al. Impact of empagliflozin added on to basal insulin in type 2 diabetes inadequately controlled on basal insulin: A 78-week randomized, doubleblind, placebo-controlled trial. Diabetes Obesity Metab 2015; 17: 936-948

[63] Rosenstock J, Jelaska A, Frappin G et al. Improved glucose control with weight loss, lower insulin doses, and no increased hypoglycemia with empagliflozin added to titrated multiple daily injections of insulin in obese inadequately controlled type 2 diabetes. Diabetes Care 2014; 37: 1815-1823

[64] Ferrannini E, Berk A, Hantel S et al. Longterm safety and efficacy of empagliflozin, sitagliptin, and metformin: An active-controlled, parallel-group, randomized, 78-week open-label extension study in patients with type 2 diabetes. Diabetes Care 2013; 36: 4015-4021

[65] Wilding JP, Woo V, Rohwedder K et al. Dapagliflozin in patients with type 2 diabetes receiving high doses of insulin: Efficacy and safety over 2 years. Diabetes Obesity Metab 2014; 16: 124-136 
[66] Nauck MA, Del Prato S, Meier J] et al. Dapagliflozin versus glipizide as add-on therapy in patients with type 2 diabetes who have inadequate glycemic control with metformin: a randomized, 52-week, double-blind, active-controlled noninferiority trial. Diabetes Care 2011; 34: 2015-2022

[67] List JF, Woo V, Morales E et al. Sodium-glucose cotransport inhibition with dapagliflozin in type 2 diabetes. Diabetes Care 2009; 32: 650-657

[68] Wilding JP, Woo V, Soler NG et al. Long-term efficacy of dapagliflozin in patients with type 2 diabetes mellitus receiving high doses of insulin: A randomized trial. Ann Internal Med 2012; 156: 405-415

[69] Cefalu WT, Leiter LA, Yoon KH et al. Efficacy and safety of canagliflozin versus glimepiride in patients with type 2 diabetes inadequately controlled with metformin (CANTATA-SU): 52 week results from a randomised, double-blind, phase 3 non-inferiority trial. Lancet 2013; 382: $941-950$

[70] Devineni D, Morrow L, Hompesch M et al. Canagliflozin improves glycaemic control over 28 days in subjects with type 2 diabetes not optimally controlled on insulin. Diabetes Obesity Metab 2012; 14: 539-545

[71] Rosenstock J, Aggarwal N, Polidori D et al. Doseranging effects of canagliflozin, a sodium-glucose cotransporter 2 inhibitor, as add-on to metformin in subjects with type 2 diabetes. Diabetes Care 2012; 35: $1232-1238$

[72] Leiter LA, Yoon KH, Arias P et al. Canagliflozin provides durable glycemic improvements and body weight reduction over 104 weeks versus glimepiride in patients with type 2 diabetes on metformin: $\mathrm{A}$ randomized, double-blind, phase 3 study. Diabetes Care 2015; 38: 355-364

[73] Sha S, Devineni D, Ghosh A et al. Pharmacodynamic effects of canagliflozin, a sodium glucose cotransporter 2 inhibitor, from a randomized study in patients with type 2 diabetes. PLoS One 2014; 9: e105638

[74] Lavalle-Gonzalez F], Januszewicz A, Davidson J et al. Efficacy and safety of canagliflozin compared with placebo and sitagliptin in patients with type 2 diabetes on background metformin monotherapy: A randomised trial. Diabetologia 2013; 56: 2582-2592

[75] Stenlof K, Cefalu WT, Kim KA et al. Efficacy and safety of canagliflozin monotherapy in subjects with type 2 diabetes mellitusinadequately controlled with diet and exercise. Diabetes Obes Metab 2013; 15: 372-382

[76] Wilding JP, Charpentier G, Hollander P et al. Efficacy and safety of canagliflozin in patients with type 2 diabetes mellitus inadequately controlled with metformin and sulphonylurea: A randomised trial. Int J Clin Pract 2013; 67: 1267-1282

[77] Schernthaner G, Gross JL, Rosenstock J et al. Canagliflozin compared with sitagliptin for patients with type 2 diabetes who do not have adequate glycemic control with metformin plus sulfonylurea: a 52-week randomized trial. Diabetes Care 2013; 36: 2508-2515

[78] Forst T, Guthrie R, Goldenberg R et al. Efficacy and safety of canagliflozin over 52 weeks in patients with type 2 diabetes on background metformin and pioglitazone. Diabetes ObesityMetab 2014; 16: 467-477

[79] Yale JF, Bakris G, Cariou B et al. Efficacy and safety of canagliflozin in subjects with type 2 diabetes and chronic kidney disease. Diabetes Obes Metab 2013; 15: 463-473

[80] Maegawa $\mathrm{H}$, Tobe $\mathrm{K}$, Tabuchi $\mathrm{H}$ et al. Baseline characteristics and interim (3-month) efficacy and safety data from STELLA-LONG TERM, a long-term post-marketing surveillance study of ipragliflozin in Japanese patients with type 2 diabetes in real-world clinical practice. Expert Opin Pharmacother 2016; 17: 1985-1994
[81] Sano M, Chen S, Imazeki H et al. Changes in heart rate in patients with type 2 diabetes mellitus after treatment with luseogliflozin: Sub-analysis of placebo controlled, double-blind clinical trials. J Diabetes Investig 2018; 9: 638-641

[82] Sano M. Hemodynamic effects of sodium-glucose cotransporter 2 inhibitors. J Clin Med Res 2017; 9: 457-460

[83] Rahman A, Fujisawa Y, Nakano D et al. Effect of a selective SGLT2 inhibitor, luseogliflozin, on circadian rhythm of sympathetic nervous function and locomotor activities in metabolic syndrome rats. J Clin Exp Pharmacol Physiol 2017; 44: 522-525

[84] Chilton R, Tikkanen I, Hehnke U et al. Impact of empagliflozin on blood pressure in dipper and non-dipperpatients with type 2 diabetes mellitus and hypertension. Diabetes Obesity Metab 2017; 19: $1620-1624$

[85] Yoshikawa T, Kishi T, Shinohara K et al. Arterial pressure lability is improved by sodium-glucose cotransporter 2 inhibitor in streptozotocin-induced diabetic rats. Hypertens Res 2017; 40: 646-651

[86] Chiba Y, Yamada T, Tsukita S et al. Dapagliflozin, a sodium-glucose co-transporter 2 inhibitor, acutely reduces energy expenditure in BAT via neural signals in mice. PLoS ONE 2016; 11: e0150756

[87] Matthews VB, Elliot RH, Rudnicka C et al. Role of the sympathetic nervous system in regulation of the sodium glucose cotransporter 2 . J Hypertens 2017; 35: 2059-2068

[88] Herat LY, Magno AL Rudnickaet C. et al. SGLT2 inhibitor-induced sympathoinhibition. A novel mechanism for cardiorenal protection. J Am Coll Cardiol Basic Trans Science 2020; 5: 169-179

[89] Ansary TM, Fujisawa Y, Rahman A et al. Responses of renal hemodynamics and tubular functions to acute sodium-glucose cotransporter 2 inhibitor administration in non-diabetic anesthetized rats. Sci Rep 2017; 7: 9555

[90] Kaur ], Young BE, Fadel PJ. Sympathetic overactivity in chronic kidney disease: consequences and mechanisms. Int J Mol Sci 2017; 18: E1682

[91] Campese VM, Kogosov E. Renal afferent denervation prevents hypertension in rats with chronic renal failure. Hypertension 1995; 25: 878-882

[92] Ye S, Zhong $\mathrm{H}$, Yanamadala $\mathrm{V}$ et al. Renal injury caused by intrarenal injection of phenol increases afferent and efferent renal sympathetic nerve activity. Am J Hypertens 2002; 15: 717-724

[93] Katholi RE, Whitlow PL, Hageman GR et al. Intrarenal adenosine produces hypertension by activating the sympathetic nervous system via the renal nerves in the dog. J Hypertens 1984; 2: 349-359

[94] Hausberg M, Kosch M, Harmelink P et al. Sympathetic nerve activity in end-stage renal disease. Circulation 2002; 106: 1974-1979

[95] Sano M. A new class of drugs for heart failure: SGLT2 inhibitors reduce sympathetic overactivity. J Cardiol 2018; 71: 471-476

[96] Schlaich MP, Bakris GL. Renal denervation: One step backwards, three steps forward. Nat Rev Nephrol 2018; 14: 602-604

[97] Rahmouni K. Leptin-induced sympathetic nerve activation: Signaling mechanisms and cardiovascular consequences in obesity. Curr Hypertens Rev 2010; 6: 104-209

[98] Yamada T, Oka Y, Katagiri H. Inter-organ metabolic communication involved in energy homeostasis: Potential therapeutic targets for obesity and metabolic syndrome. Pharmacol Ther 2008; 117 : 188-198

[99] Conde SV, Sacramento JF, Guarino MP et al. Carotid body, insulin, and metabolic diseases: Unraveling the links. Front Physiol 2014; 5: 418

[100] Guyenet PG. Putative mechanism of salt-dependent neurogenic hypertension: cell-autonomous activation of organum vasculosum laminae terminalis neurons by hypernatremia. Hypertension 2017; 69: $20-22$ 
[101] Marx N, McGuire DK. Sodium-glucose cotransporter-2 inhibition for the reduction of cardiovascular events in high-risk patients with diabetes mellitus. Eur Heart J 2016; 37: 3192-3200

[102] Cherney DZ, Perkins BA, Soleymanlou N et al. Renal hemodynamic effect of sodium-glucose cotransporter 2 inhibition in patients with type 1 diabetes mellitus. Circulation 2014; 129: 587-597

[103] Ansary T, Nakano D, Nishiyama A. Diuretic effects of sodium glucose cotransporter 2 inhibitors and their influence on the renin-angiotensin system. Int J Mol Sci 2019; 20: 629

[104] Rajasekeran H, Kim SJ, Cardella C] et al. Use of canagliflozin in kidney transplant recipients for the treatment of type 2 diabetes: a case series. Diabetes Care 2017; 40: e75-e76

[105] Thomas M, Cherney D. The actions of SGLT2 inhibitors on metabolism, renal function and blood pressure. Diabetologia 2018; 61: 2098-2107

[106] Bonner C, Kerr-Conte J, Gmyr V et al. Inhibition of the glucose transporter SGLT2 with dapagliflozin in pancreatic alpha cells triggers glucagon secretion. Nat Med 2015; 21: 512-517
[107] Merovci A, Solis-Herrera C, Daniele G et al. Dapagliflozin improves muscle insulin sensitivity but enhances endogenous glucose production. J Clin Invest 2014; 124: 509-514

[108] DeFronzo R, Lewin A, Patel S et al. Combination of empagliflozin and linagliptin as second-line therapy in subjects with type 2 diabetes inadequately controlled on metformin. Diabetes Care 2015; 38: 384-393

[109] Rosenstock J, Hansen L, Zee P et al. Dual add on therapy in type 2 diabetes poorly controlled with metformin monotherapy: A randomized double-blind trial of saxagliptin plus dapagliflozin addition versus single addition of saxagliptin or dapagliflozin to metformin. Diabetes Care 2015; 38: 376-383

[110] Jordan J, Tank J, Heusser $\mathrm{K}$ et al. The effect of empagliflozin on muscle sympathetic nerve activity in patients with type II diabetes mellitus. J Am Soc Hypertens 2017; 11: 604-612

[111] Kubota Y, Yamamoto T, Tara $S$ et al. Effect of empagliflozin versus placebo on cardiac sympathetic activity in acute myocardial infarction patients with type 2 diabetes mellitus: Rationale. Diabetes Ther 2018; 9: 2107-2121 